\title{
Adoption of Instructional Videos for Teaching and Learning Safety Precautions in Vocational Schools for Achieving Sustainable Educational Development Goals in Nigeria
}

\author{
Kabiru Bawa*, Ayoola Ajelabi, PhD, Shuaibu Saminu \\ Department of Science and Technical Education, Yusuf Maitama Sule University, Kano, Nigeria
}

*Corresponding Author: Kabiru Bawa, Department of Science and Technical Education, Yusuf Maitama

Sule University, Kano, Nigeria

\begin{abstract}
Instructional videos plays an important role in pedagogy. Essentially, instructional videos for teaching and learning workshop safety precautions becomes a tool for sustaining safety at work. This paper examined the concept of instructional video as well as the benefits when applied to instructions. It further looked at the status of safety precautions in Kano State Technical Colleges. In addition, the paper focused on the sustainable development goals in general and education goals in particular. The current trends in the use of safety precautions in technical schools were analysed. It was realized that instructional videos were hardly applied to teach safety precautions in workshops. This paper therefore looked at the prospect of adopting instructional videos to achieve educational development goal. The challenges associated with the integration were discussed. The paper concluded by stating that there is need to provide classrooms with videos as an instructional tool in order to improve the process of learning safety precaution that would address the situation, because video is a tool that have a powerful impact on students retention of information as well as on students engagement. Finally, it was suggested that all gadgets and equipment needed for playing and watching instructional videos should be provided in all the schools; and that short, complete and meaningful videos should be provided to address the introvert and extrovert students when teaching and learning safety precautions.
\end{abstract}

Keywords: Instructional Videos, Teaching and Learning, Safety Precaution, Vocational Schools, SDGs

\section{INTRODUCTION}

Video plays an important role in education in terms of its integration into traditional classes. In the earlier times, media (including audio and video) had been used for recreation/leisure purposes mostly for entertainment and in few instances for learning. However, the impact of media on learning as well as motivation for learning is directly related to viewer/learners' beliefs and expectations. This is because learners decide what to view based on their likes but not based on designed instructional package or curriculum.

The adoption of instructional videos to support teaching and learning was not so hard, mainly becauselearners have cultivated the habit of watching videos for leisure purposes. Generally, instructional videos in teaching and learning plays an important role towards acquisition of knowledge. However, each instructional video should be developed in consideration of the level of the students' interests and abilities (Donkor, 2010).

The use of instructional videos for teaching and learning workshop safety precaution can be viewed as a process or step by step motion procedures on how best students can use hardware and machine tools and any other practical equipment in an organised manner in such a way that hazard is minimized or totally prevented (Denning, 2000). Practical sessions usually help in reinforcing theoretical knowledge acquired by learners, especially in the area of skill acquisition training. Donkor (2010) explained that, users of video-based instructional materials are more likely to spend relatively less time performing specific tasks during practical lessons. He further stated that, there would be less spoilage/wastage of consumables, reduced incidence of damage to equipment, and reduced accidents among users of video-based instructional materials during hands-on practical lessons. 
Thus, as much as possible, when selecting delivery options for the teaching and learning of safety precaution in practical skills, instructional videos played an important role above print materials in terms of reducing accidents and wastage of time. Hence, users of video-based instructional materials are more likely to spend relatively less time performing specific tasks during practical lessons.

Additionally, there would be less wastage of consumables, reduced incidence of damage to equipment, and reduced accidents among users of video-based instructional materials during hands-on practical lessons. The identified benefits associated with the use of video-based instructional materials in teaching practical lessons could help to reduce costs when there is less spoilage and waste of materials, reduced injuries to learners, and reduced damage to equipment. This could help to compensate for the cost of producing the practical lessons on video compact discs for use by distant learners.

Sustainable Development Goals (SDGs) identified education as a key sector towards transforming the world. It aims at ensuring inclusive and equitable quality education and the promotion of lifelong learning opportunities for all, in which science, technical and vocational education skills are included. To achieve this goal in education that required practical skills, instructional videos can provide easy, quick and permanent learning guide to achieve sustainable educational goals.

SDG encompasses educational development from pre-basic education to higher education and even beyond. It include technical and vocational skills development. United Nation declaration believes that education is a human right for all throughout life and that access must be matched by quality (UNESCO, 2015). They further said that it is vital for education systems to ensure that all children, youth and adults are learning and acquire relevant skills with proficiency in literacy.

Hence, there is an urgent need for children, youth and adults to develop throughout life the flexible skills and competencies they need to liveand work in a more secure, sustainable, interdependent, knowledge-based and technology-driven world, in which instructional videos will help toward that. SDG4-Education 2030 aim at ensuring that all individuals acquire a solid foundation of knowledge, develop creative and critical thinking and collaborative skills, and build curiosity, courage and resilience.

Therefore, the study would be of significant use to community, teachers and students because it will provide a guide on the importance of using instructional videos for teaching and learning safety precautions in the area of science, technical and vocational courses, because there is need for an easy, quick and qualitative way of providing concrete learning among students for achieving sustainable educational goals as stated by the United Nations.

\section{CONCEPT OF INSTRUCTIONAL VIDEOS}

It is a video that is used for instructional purpose. Instructional videos can be used in a course to introduce new skills, knowledge, safety habit or behaviour to be learned or reinforced. Higgin (2018) said that, when it comes to video, students should not just get it; they need to have something to say about it. He further said that, it makes students active and reactive viewers, comprehending and critiquing, reading and reacting, getting and giving knowledge. Students may not always enjoy it, but watching a video more than once is key to going from passive to active and all the way to reactive viewing. Video is now recognized by most educators as a powerful communications medium which, in combination with other learning resources and instructional strategies, can perform a vital role in modern education (Denning 2000). He further stated that, video may help to promote learning in students with high visual orientation in their learning styles. Video can also provide visuallycompelling access to information for many learners with reading difficulties who might miss learning opportunities provided solely by print-based materials. Videos can be used to demonstrate specific manual skills or physical processes, either at normal speed, in slow motion, or speeded up to reveal relationships, principles, or practices. Videos can provide visual access to situations or experiments that would otherwise be too dangerous or expensive for students to experience personally.

Students usually spend many hours being entertained by television and movies. Teachers face the challenge of breaking students' passive viewing habits. When videos are properly integrated into instruction, they do not function merely to provide diversion - they promote learning through active engagement of students' mental processes (Denning, 2000).Using video or film in classroom 
instruction has the advantage of presenting abstract ideas in a realistic context, which helps students grasp the abstract ideas more easily and to retain the material longer.

Taslibeyaz et al., (2017) outlined that, in the context of medical education from 2000 to 2014, predominantly case studies showed that watching videos was beneficial for gaining clinical skills, changing attitudes, encouraging cognitive learning and retaining knowledge. Similarly, in a peerreviewed qualitative and quantitative papers spanning from 2003-2013 sourced from 7 major databases and 21 academic journals, Yousef et al. (2014) found some evidence that use of video-based learning saw improvements in teaching methods and learning outcomes.

Furthermore, the visual benefits of video provide a vehicle for increasing access to practical demonstrations. Students can learn from field experts having the opportunity to view close-up expert illustrations, and with the option to view them repeatedly if necessary (Ramlogan et al., 2014, Cooper and Higgins, 2015).

\subsection{Benefits of Instructional Videos}

There are so many benefit to be derived from instructional videos. Among these are:

\subsubsection{Improve Teaching and Learning Outcome}

The benefits of video provide a vehicle for increasing access to practical demonstrations. It gives room to the teacher for pausing the video at some point for further explanation, and the students can replay some part of the video. It also create opportunities for self-study. There are evidences of increase students' performance as Yousef et al. (2014) identified.

\subsubsection{Reduce Bulky Print Based Materials}

The video instructional content explains more and only few white paper printed document will be provided to the students. Hegeman (2015) compared students performance in two schools Algebra courses; one that relied heavily on publisher-generated resources as the content provider and the other that used instructor-generated videos as the primary sources of course content and instruction. Students enrolled in the latter course performed significantly better on all exams and assignments than those enrolled in the former course.

\subsubsection{Increase Self-Paced Learning}

Students can learn at their own will and design, they can play the videos at the time and location they want if the recorded video is at the student disposal (personal computer or cell phone). Distasio (2016) was of the view that one can play video lecture in all browsers and mobile devices. The most significant benefits of instructional videos are that learners can stop, rewind, pause and then manipulate the timeline of studying.

\subsubsection{Time Management}

Instructional videos can make an impact in a considerable short period of time. The combination of educational video, audio and/or images allow users to obtain information easily, particularly the knowledge concepts and skills.

\section{CONCEPT OF TEACHING AND LEARNING}

Teaching is the act of delivering learning contents to the learner. A typical classroom activity focuses on a segment of a curriculum topic such as a significant concept, understanding, principle or skill (Wells, 2002). Teaching activity is a goal-oriented sequence of actions, which may include carrying out an experiment, writing an essay or a teacher-student discussion.

Teaching is a set of events, outside the learners which are designed to support internal process of learning. Teaching (Instruction) is outside the learner while learning is internal to learners. Motives are not seen, but, behaviours are seen, and learning is both a motive and behaviour. However, only behaviour is seen, learning is internal and performance is external (Sequeira, 2012).

Learning is about a change: the change brought about by developing a new skill, understanding a scientific law and change in attitude. The change is not merely incidental or natural in the way that our appearance change. Learning is a relatively a permanent change, which is usually brought about 
for a purpose. When we attend a training, read a book or read a paper, we set out and prepare to learn. Learning is about the transformations in people based on actual involvement in activities.

Teacher is like a coach who always support his players in learning and demonstrating mastery. Similarly, as coach he must help the players to develop functional knowledge and skill, give opportunities for practice, facilitate group discussion and keep an eye on the time and structure of the players learning.

\section{Safety Precautions in TeChnical SchoOlS}

A proactive measure taken in order to protect against possible danger, failure, or injury is referred to as safety precaution. Collins dictionary (1819) define safety precautions as a step that is taken in order to ensure that something is safe and not dangerous.

Safety precaution plays an important role in schools and technical schools. Ensuring student safety has been part of the ethical framework for decades. However, technical schools have a primary duty of safeguarding the staff and students in their care while at the same time creating the 'risk aware, but not risk adverse' citizens of tomorrow.

\subsection{Basic Rules for Workshop Safety}

Safety in the technical schools workshop is everyone's responsibility. Deakin University (2017) identified some of the safety rules to ensure in the workshop by all students and staff as follows;

- Read instructions carefully and notify the workshop staff before entering the workshop and before using any tool.

- Staff and Students who are drunk should not be permitted in the workshop.

- Students who are with any health problems that may affect workplace safety (e.g. medication, epileptic fits) must report these conditions to the workshop staff.

- Do not eat food or drink in the workshop.

- Wear the correct protective equipment (boot, head, hearing and eye protectors)

- Permission must be obtained from workshop staff before using all chemicals (e.g. glues, paints, etc.).

- Immediately notify the workshop supervisor of any faulty or broken equipment.

- Make sure your work piece is fixed securely before work commences on it.

- Keep clear of any person operating tools and machinery (bumping an operator or get tangled in the lead could cause serious injury to you or the operator).

- Do not talk to anyone operating machinery and electrical equipment.

- Keep your work area neat and tidy.

- Clean up any spills immediately.

- Wash hands after using chemicals, equipment and materials

- All loose clothing and long hair (e.g. shirts hanging out) must be stuck and tied up.

- Do not work with rings and loose jewellery, remove them before operating machinery they can cause hazard.

\section{The Sustainable DeVelopment Goals}

The 2030 Agenda for Sustainable Development, adopted by all United Nations (UN) Member States in 2015 provides a shared blueprint for peace and prosperity for people and the planet, now and into the future (UN, 2015).

The vision of the 2030 agenda for the SDGs is to envisage a world free of poverty, hunger, disease and want, where all life can thrive. We envisage a world free of fear and violence; a world with universal literacy; a world with equitable and universal access to quality education at all levels, to 
health care and social protection, where physical, mental and social well-being are assured; a world where we reaffirm our commitments regarding the human right to safe drinking water and sanitation and where there is improved hygiene; and where food is sufficient, safe, affordable and nutritious. A world where human habitats are safe, resilient and sustainable and where there is universal access to affordable, reliable and sustainable energy.

Also among the vision they envisage for is a world of universal respect for human rights and human dignity, the rule of law, justice, equality and non-discrimination; of respect for race, ethnicity and cultural diversity; and of equal opportunity permitting the full realization of human potential and contributing to shared prosperity. A world which invests in its children and in which every child grows up free from violence and exploitation. A world in which every woman and girl enjoys full gender equality and all legal, social and economic barriers to their empowerment have been removed. A just, equitable, tolerant, open and socially inclusive world in which the needs of the most vulnerable are met.

Lastly, the agenda envisage for a world in which every country enjoys sustained, inclusive and sustainable economic growth and decent work for all. A world in which consumption and production patterns and use of all natural resources - from air to land, from rivers, lakes and aquifers to oceans and seas - are sustainable. One in which democracy, good governance and the rule of law as well as an enabling environment at national and international levels, are essential for sustainable development, including sustained and inclusive economic growth, social development, environmental protection and the eradication of poverty and hunger. One in which development and the application of technology are climate-sensitive, respect biodiversity and are resilient. One in which humanity lives in harmony with nature and in which wildlife and other living species are protected (UN, 2015).

\subsection{General Goals}

The United Nation came up with 17 Sustainable Development Goals (SDGs), which emphasised call for action by all countries - developed and developing - in a global partnership. They recognize that ending poverty and other deprivations must go hand-in-hand with strategies that improve health and education, reduce inequality, and spur economic growth - all while tackling climate change and working to preserve our oceans and forests (UN, 2015). The 17 goals as itemized by the UN 2030 agenda for sustainable development are as follows:

Goal 1. End poverty in all its forms everywhere

Goal 2. End hunger, achieve food security and improved nutrition and promote sustainable agriculture

Goal 3. Ensure healthy lives and promote well-being for all at all ages

Goal 4. Ensure inclusive and equitable quality education and promote lifelong learning opportunities for all

Goal 5. Achieve gender equality and empower all women and girls

Goal 6. Ensure availability and sustainable management of water and sanitation for all

Goal 7. Ensure access to affordable, reliable, sustainable and modern energy for all

Goal 8. Promote sustained, inclusive and sustainable economic growth, full and productive employment and decent work for all

Goal 9. Build resilient infrastructure, promote inclusive and sustainable industrialization and foster innovation

Goal 10. Reduce inequality within and among countries

Goal 11. Make cities and human settlements inclusive, safe, resilient and sustainable

Goal 12. Ensure sustainable consumption and production patterns

Goal 13. Take urgent action to combat climate change and its impacts*

Goal 14. Conserve and sustainably use the oceans, seas and marine resources for sustainable development

Goal 15. Protect, restore and promote sustainable use of terrestrial ecosystems, sustainably manage forests, combat desertification, and halt and reverse land degradation and halt biodiversity loss 
Goal 16. Promote peaceful and inclusive societies for sustainable development, provide access to justice for all and build effective, accountable and inclusive institutions at all levels

Goal 17. Strengthen the means of implementation and revitalize the global partnership for sustainable development

\subsection{Educational Development Goal (Goal 4)}

Education transforms lives and is at the heart of UNESCO's mission to build peace, eradicate poverty and drive sustainable development. UNESCO believes that education is a human right for all throughout life and that access must be matched by quality. The Organization is the only United Nations agency with a mandate to cover all aspects of education. It has been entrusted to lead the Global Education 2030 Agenda through Sustainable Development Goal four (4). The roadmap to achieve this is the Education 2030 Framework For Action (FFA). (UNESCO, 2019)

Obtaining a quality education is the foundation to creating sustainable development. In addition to improving quality of life, access to inclusive education can help equip locals with the tools required to develop innovative solutions to the world's greatest problems.

Over 265 million children are currently out of school and $22 \%$ of them are of primary school age. Additionally, even the children who are attending schools are lacking basic skills in reading and arithmetic. In the past decade, major progress has been made towards increasing access to education at all levels and increasing enrollment rates in schools particularly for women and girls (UNESCO, 2019). Basic literacy skills have improved tremendously, yet bolder efforts are needed to make even greater strides for achieving universal education goals. For example, the world has achieved equality in primary education between girls and boys, but few countries have achieved that target at all levels of education.

The reasons for lack of quality education are due to lack of adequately trained teachers, poor conditions of schools and equity issues related to opportunities provided to rural children. For quality education to be provided to the children of impoverished families, investment is needed in educational scholarships, teacher training workshops, school building and improvement of water and electricity access to schools (UN, 2015).

The $4^{\text {th }}$ goal of the 2030 agenda for sustainable development emphasised that the world need to ensure inclusive and equitable quality education and promote lifelong learning opportunities for all. The goal target as itemized by UN are as follows.

- By 2030, ensure that all girls and boys complete free, equitable and quality primary and secondary education leading to relevant and Goal-4 effective learning outcomes

- By 2030, ensure that all girls and boys have access to quality early childhood development, care and preprimary education so that they are ready for primary education

- By 2030, ensure equal access for all women and men to affordable and quality technical, vocational and tertiary education, including university

- By 2030, substantially increase the number of youths and adults who have relevant skills, including technical and vocational skills, for employment, decent jobs and entrepreneurship

- By 2030, eliminate gender disparities in education and ensure equal access to all levels of education and vocational training for the vulnerable, including persons with disabilities, indigenous peoples and children in vulnerable situations

- By 2030, ensure that all youth and a substantial proportion of adults, both men and women, achieve literacy and numeracy

- By 2030, ensure that all learners acquire the knowledge and skills needed to promote sustainable development, including, among others, through education for sustainable development and sustainable lifestyles, human rights, gender equality, promotion of a culture of peace and nonviolence, global citizenship and appreciation of cultural diversity and of culture's contribution to sustainable development

Also by 2030 the UN through its sustainable development goal 4 for achieving inclusive and equitable quality education want to:

- Build and upgrade education facilities that are child, disability and gender sensitive and provide safe, nonviolent, inclusive and effective learning environments for all 
- By 2030, substantially expand globally the number of scholarships available to developing countries, in particular least developed countries, small island developing States and African countries, for enrolment in higher education, including vocational training and information and communications technology, technical, engineering and scientific programmes, in developed countries and other developing countries

- By 2030, substantially increase the supply of qualified teachers, including through international cooperation for teacher training in developing countries, especially least developed countries and small island developing states

\section{Current Trends in the Use of Safety Precautions in Technical Schools}

Technical schools are established and designed mainly to produce skilled craftsmen who will be able to perform basic functions in maintenance work both in private and public sector. Unfortunately, practical skills acquisition in Nigerian technical schools nowadays are battling with numerous problems among which are poor teaching and practical strategies (Odu, 2006). The teaching of technical subjects had been too theoretical that many students prefer subjects in Arts and Social Sciences because there is no longer much emphasis on the learners' practical skills acquisition in technical schools. Teachers in most cases use lecture method only in a programme instead of applying a variety of strategies like demonstration and discussion or guided discovery and discussion (Odu, 2006). Isah (2003) observed that the usual practice is that students' practical projects are inspected at the end of the process. However, there is no supervision during the practical process to ensure that safety precautions are adhered to.

This observation still persists as supported by Udofia, Ekpo, Nsa\&Akpan (2012). They reported that wrong approach to teaching, supervisory and assessment strategies of practical subjects in technical schools rather than impart practical skills to students, do produce students who are ill-equipped with practical skills. This eventually led to inadequate creative power and unable to secure employment. Inability to put into practice what is taught to students in technical schools also cause relative backwardness of most societies. The researchers also observed that despite many years of teaching technical trade subjects in Technical Schools of Kano State, the lucrative nature of the trades and low capital requirement for establishing trade centres, not many graduates of the trade possessed adequate safety and practical skills that will enable them to effectively fit into the world of work. This may be caused by poor acquisition of instructional guide of the practical skills by the students. To worsen the situation, there are obsolete and inefficient practical teaching materials and equipment at the technical trade centres in Technical Schools of Kano State.

Salihu (2010) asserted that practical teaching materials available in most technical schools in Kano State are obsolete and not functional and consumable materials do not commensurate with students' population. As a result of this, technical graduates that were produced over the years were deficient in practical skills. In a similar perspective, He further reported that there were wrong approaches to teaching and evaluation of practical subjects in technical schools. Rather than imparting skills to students, the system was producing students who are ill-equipped with practical skills. Hence, the researchers identified that students in Kano Technical Schools receive ineffective instruction and become weak in practical skills due to wrong approach to teaching, supervising, and assessment.

Nigeria is a country where laudable policies are often initiated, but it is quickly rendered impotent by officialdom. Also vocational/technical education have been given little weight by the authorities concerned over the years. Equipment provision and staff development have suffered immensely (Akaninwor, 2008), and the trend remain same till date. Any technical education that needs to be relevant must ensure that processes and programmes based on current global technological innovations are incorporated. Relevant instructional strategies to be adopted should include demonstration, simulation and individual/group projects for the students. Programmed instruction which is another powerful tool for instruction should also be employed. Computers have now become permanent features in technical training institutions and workshops in Asia, Europe and America. Some African and South American countries are also in the race, but Nigeria is yet to make a head way. Technical drawing equipment such as drawing board, T-square, set square, etc., have been relegated to the background in European and American schools due to the upsurge in computer graphics and computer aided design (CAD). The replication of computer assisted instruction (CAl) in Nigeria is quite imperative in view of its advantages. 


\section{Prospects of Adopting Instructional Videos to Achieve Educational DEVELOPMENT GOALS}

These days, education of learners moving away from the traditional instructional approach to video supported instructions. Video based learning is described as the instructional process of obtaining information, knowledge and skills along with the principled support of video resources (Albo, Hernandez-Leo, Barcelo \& Sanabria, 2015).

Hence, many instructional organisations are providing classrooms with videos as an instructional tools in order to improve the process of learning. Previous studies show that Video supported learning and instruction has been showing its benefits in education. The videos can be used in many ways in order to make an impact in teaching and learning. For example, it can encourage instructors to consider it for flipped classroom approach, where students can study the instructional material at their own pace and afterward learn the detail more deeply in the class time (Ozdamli\&Ozdal, 2018; Yousef, Chatti\& Schroeder, 2014).

Moreover, instructional videos can facilitate practical learning by providing students with basic steps and ways on how to go with the real practical package, and how to conduct it in an accident free environment. Consequently, it enable learners to obtain the skills in organising and conducting practical in an effective way. Additionally, video can be useful as instructor in representing the process or interactive facts in order to help in mastery of studying, where learners can see convoluted mechanical or clinical procedures many times when they are needed. Besides, the modern web-based media players do have interactive features that can be utilised in order to enhance 'active learning' methods with learners. Besides, Video based instructional contents provide learners with producing opportunity of authentic learning and also how academics from the research-based view and advocacy can be encouraged by instructional videos (Galbraith, 2004).

Although the impact of video and multimedia technologies in educational outcomes is a field of ongoing research, Beheshti, Taspolat, Kaya \&Sapanca, (2018) summarized the impact of video in education from the following three concepts:

- Interactivity with content (the learner relates to visual content, whether verbally, by note taking or thinking, or by applying concepts)

- Engagement (the learner connects to the visual content, becoming drawn in by video, whether ondemand or real-time)

- Knowledge transfer and memory (the learner may remember and retain concepts better than with other instructional media). Because video combines many kinds of data (images, motion, sounds, text) in a complementary fashion, learning can be adjusted more easily than with other tools to the diverse learning styles and individual learning pace of students. With video, the learners has more control over the information they receive with an additional opportunity for deeper learning by being able to stop, rewind, fast-forward, and replay content as many times as needed.

However, successful adoption of instructional video technologies in the classroom is a process that requires a clear vision of education transformation, proper integration with curricula and alternative methodologies, as well as the continuous engagement and support of instructors, learners, administrators and parents. Hence, the use of video begins to meet the needs of today's and tomorrow's learners. Video help instructors addresses the challenges of different learning styles and enhance the way in which today's children and youth access, absorb, interpret, process and use the information for several purposes.

Video is a tool that can have a powerful impact on students retention of information as well as on students engagement. As 21st century learners need to be prepared for global citizenship and to collaborate with others especially in the area of practical skills, video will be a powerful tool in the hands of students. Consequently, the rapid availability of video tools would prop up the changing role of the instructors. Instructors will increasingly perform the instructing role both in person and over distance, across geographies and time and across different media. This will turn the world into a universal multimodal classroom, giving learners, instructors, and their institutions access to huge amounts of content worldwide for their practical classes. 


\section{Challenges of USing InStructional Videos}

Instructional videos have been in the field of teaching and learning for several years, in which television, computers and later mobile devices have grown rapidly around it. Learning through video have become one of the comfortable and speedy instructional approaches in education.

However, there are many challenges revolving round the use of instructional videos. It ranges from equipment needs to individualized learning. Below are some of the drawbacks of instructional video:

- It is necessary to have equipment: The most important identified problem with instructional video is the need of equipment such as TV, computer or mobile devices in order to watch the videos. Hence, many people around the world, particularly those in the rural areas don't have access to these video due to this simple reason (Galbraith, 2004).

- Hard to edit videos: one of the issue with instructional video is that it is static in nature, once it is created, it will be hard to edit it in case of any corrections. Notwithstanding, there are some other options to be used such as using some video platforms in order to solve the problem rather than reissuing it (Brainscape Team, 2015).

- Videos are individualistic in nature: another problem with studying via video is that it encourage individualism which make learning more difficult. One of the benefits of instructional videos is that you can learn alone in privacy at home, this is also one of its disadvantages. Learning in group or as a team enables the learners to share their skills and solve the problems within shortest possible time. However, the benefit of instructional video is that learners can study in their pace, but it can also be considered as its drawbacks (Galbraith, 2004).

- Instructional approach: the approach of some instructional videos utilise may not entice some learners due to lack of experience, particularly, when learners are required to do some tasking activities or be pragmatists. Learners may prefer reading words and having discussion in order to do any task rather than watching instructional videos (Michael, 2015).

- Isolation issue: There are learners who are extroverts in nature, they are more comfortable to ask their problems directly and get instant response while learning a new subject. Instructional videos doesn't always provide students with instant response, and so learners may feel isolated as they are not supported and reassured by their instructors.

\section{SugGeStions}

The study looked into current trends regarding safety precautions in Technical Schools in Kano state, Nigeria. The challenges encountered while using instructional video and the prospects of adopting instructional videos for teaching and learning safety precautions were designed. Below are the suggestions made for proper utilisation of instruction videos for teaching and learning safety precautions in technical schools for achieving sustainable development goals.

- All gadgets and equipment needed for playing and watching instructional videos should be provided in all the schools: they should be in good working conditions. The television, computer, light source, viewing room, internet (if necessary) and other accessory should be functional. The instructor also should be around to provide clarification where necessary.

- Provision of short and complete video: instructional videos should be short in length and must contain a complete meaning of what it is meant for. Lengthy videos can be subdivided into an understandable sub-videos for easy understanding of the learners.

- Group working: learners should be allowed to watch the video in groups and make their own similar instructional video in order to show their level of understanding of the original video.

- The instructors should accommodate introvert and extrovert students: introvert and extrovert students should be accommodated during instruction with the help of instructional videos.

- The instructor should watch the instructional video clips ahead of the lesson, understand it and build it into the lesson.

Ajelabi (2005) itemized how instructional videos could be incorporated into classroom lessons. These are:

- Prepare the class: arrange the seats and ensure that all the learners are facing the television screen. Prior to this time, the instructor needs to ensure that all the sockets and other gadgets are in good working condition. 
- Instructor should explain the topic and what it cover.

- Motivate the learners to pay attention so as to achieve the instructional objectives.

- After the lesson, arrange question and answer session. You may need to review the lesson based on the feedback.

- Finally, the instructor would carry out an evaluation.

\section{CONCLUSION}

In the recent past, using video in class was meant for showing movies by using DVD or video cassette player to learners. Nowadays instructional videos take a more prominent place in the instructional process especially in subject that requires practical skills. Utilisation of instructional videos for teaching and learning help toward achieving proficiency in training by learners. Use of videos in learning provide a significant, flexible and autonomous education. The use of instructional video approach is superior to the present text-based learning while teaching certain safety precaution for practical skills.

Instructional videos can be combined with online learning systems in classroom environments using portal as E-class when teaching safety precautions. The advantage of using instructional videos for teaching is to ensure inclusive and equitable quality education for children, youth and adults, while promoting lifelong learning opportunities for all (UNESCO, 2015).Instructional videos help to engage and inspire students when learning safety precaution skills and other educating activities.

\section{REFERENCES}

[1] Ajelabi, A. (2005). Production and Utilisation of Educational media. Lagos. Raytel Publications Limited.

[2] Akaninwor, G. I. K. (2008). Educational Technology Theory and Practice. Port Harcourt: Wilson Publishing Company Limited

[3] Albo, L., Hernandez-Leo, D., Barcelo, L. \&Sanabria, L. (2015). Video-based learning in higher education: the flipped or the hands-on classroom? EDEN Annual Conference, Barcelona, Spain.

[4] Beheshti,M., Taspolat, A., Kaya, S.O. \&Sapanca, F. H. (2018). Characteristics of instructional videos. World Journal on Educational Technology: Current Issues. 10(1), 061-069.

[5] Brainscape Team. (2015). 6 pros and cons of video learning. Retrieved from https://www.brainscape.com/ blog/ 2014/11/video-learning-pros-cons/

[6] Collins dictionary. (1819). https://www.collinsdictionary.com/dictionary/english/safety-precaution

[7] Cooper, D. and Higgins, S. (2015), 'The effectiveness of online instructional videos in the acquisition and demonstration of cognitive, affective and psychomotor rehabilitation skills', British Journal of Educational Technology, vol. 46(4), 768-779.

[8] Deakin University. (2017).Faculty of Science, Engineering \& Built Environment. https://www.deakin. edu.au/students/faculties/sebe/abe-students/workshop/rules-safety

[9] Denning P. (2000). Practicing Harm Reduction Psychotherapy: An Alternative Approach to the Addictions. New York: Guilford Press.

[10] Distasio, S. (2016). Top 3 advantages of video-based training. Retrieved from http://www.epathlearning. com/uncategorized/the-top-3-advantages/

[11] Donkor, F. (2010). The Comparative Instructional Effectiveness of Print-Based and Video-Based Instructional Materials for Teaching Practical Skills at a Distance. International Review of Research in Open and Distance Learning, 11(1).

[12] Galbraith, J. (2004). Adult learning methods: a guide for effective instruction (3rd ed.). Malabar, FL: Krieger Publishing Company.

[13] Hegeman, J. S. (2015). Using instructor-generated video lectures in online mathematics courses improves student learning. Online Learning, 19(3), 70-87.

[14] Higgin, T. (2018). Using Video Effectively in the Classroom. Available at: https://www.commonsense. org/education/articles/using-video-effectively-in-the-classroom

[15] Isah, M. P. (2003). Effective management of workshop resources in vocational technical education for National development, Journal of Nigeria Association of Teachers of Technology, vol. 5(6), 146-146.

[16] Michael, J. G. (2015). The advantages and disadvantages of eLearning. Retrieved from http://www. optimussourcing.com/learninghintsandtips/the-advantages-and-disadvantages-of-elearning 
[17] Odu, K. O. (2006). Improving the quality of technology education in Nigerian Secondary School, African Journal of Education and Development, vol. 5 (1), 88-94.

[18] Ozdamli, F. \&Ozdal, H. (2018). Developing an instructional design for the design of infographics and the evaluation of infographic usage in teaching based on teacher and student opinions. EURASIA. Journal of Mathematics, Science and Technology Education, vol. 14(4), 1197-1219. doi:10.29333/ejmste/81868

[19] Ramlogan, S., Raman, V. and Sweet, J. (2014), 'A comparison of two forms of teaching instruction: video vs. live lecture for education in clinical periodontology', European Journal of Dental Education, vol. 18(1), 31-38.

[20] Salihu, Y. (2010). Strategies for improving teaching and learning practical skills in motor vehicle mechanics trade in technical colleges in Gombe State, Journal of Vocational and Technical Educators, vol. 2 (2), 47-54.

[21] Sequeira, A. H. (2012). Introduction to Concepts of Teaching and Learning. Available at: https:// ssrn.com/abstract $=2150166$

[22] Taslibeyaz, E., Aydemir, M. and Karaman, S. (2017), 'An analysis of research trends in articles on video usage in medical education', Education and Information Technologies, vol. 22(3), 873-881.

[23] Udofia, A. E., Ekpo, A. B., Nsa, S. O. \&Akpan, E. O. (2012). Instructional variables and students' acquisition of employable skills in vocational education in Nigerian technical colleges, International Journal of Engineering and Social Science, vol. 2 (7), 13-15.

[24] UN (2015). Available at:https://sustainabledevelopment.un.org/post2015/transformingourworld

[25] UNESCO (2015). Education 2030Incheon Declaration: Towards inclusive and equitable quality education and lifelong learning for all. Available at: https://unesdoc.unesco.org/ark:/48223/pf0000245656

[26] UNESCO (2019). Available at: https://en.unesco.org/themes/education, or https://unesdoc.unesco.org/ark: 148223/pf0000368753

[27] Wells, G. (2002). The role of dialogue in activity theory. Mind, Culture, \& Activity, 9(1), 43-66.

[28] Yousef, A. M. F., Chatti, M. A. and Schroeder, U. (2014), Video-Based Learning: A Critical Analysis of The Research Published in 2003-2013 and Future Visions, in 'The Sixth International Conference on Mobile, Hybrid, and On-line Learning : eLmL 2014; Barcelona, Spain, from March 23, 2014 to March 27, 2014', IARIA, Barcelona, pp. 112-119.

\section{AUTHORS' BIOGRAPHY}

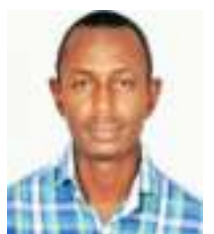

Kabiru Bawa, NCE (Technical), B. Tech. (Ed) Electrical/Electronics, M. Tech. Electronics and control Engineering is currently a Lecturer in the Department of Science and Technical Education, Yusuf Maitama Sule University, Kano. His research interests are Technical and Vocational Education and Training, ICT in Education and Entrepreneurship Education.

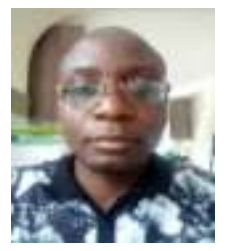

Peter Ayoola Ajelabi, Ph.D is an Associate Professor and Head, Department of Science and Technical Education at Yusuf Maiatama Sule University, Kano, Nigeria. He was formerly the Director, General Studies Unit, in same University. His research interests are Educational Technology, Computer in Education and Teacher Education.

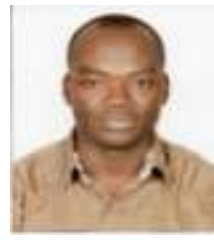

Shuaibu Saminu, NCE (Technical), B. Tech. (Ed) Woodwork, M. Tech. Construction Engineering and Management is currently a Lecturer in the Department of Science and Technical Education, Yusuf Maitama Sule University, Kano. His areas of specialization are Technical and Vocational Education and Entrepreneurship Education.

Citation: Kabiru Bawa, et.al. "Adoption of Instructional Videos for Teaching and Learning Safety Precautions in Vocational Schools for Achieving Sustainable Educational Development Goals in Nigeria". International Journal of Humanities Social Sciences and Education (IJHSSE), vol. 6, no.11, 2019, pp. 9-19. doi: http://dx.doi.org/10.20431/2349-0381.0611002.

Copyright: (C) 2019 Authors. This is an open-access article distributed under the terms of the Creative Commons Attribution License, which permits unrestricted use, distribution, and reproduction in any medium, provided the original author and source are credited. 